\title{
Slotted Circularly Polarized Microstrip Antenna for RFID Application
}

\author{
Sanjeev KUMAR ${ }^{1}$, Rajesh Kumar VISHWAKARMA ${ }^{1}$, Ravi KUMAR ${ }^{1}$, \\ Jaume ANGUERA ${ }^{2}$, Aurora ANDUJAR ${ }^{2}$ \\ ${ }^{1}$ Dept. of Electronics \& Communication Eng., Jaypee University of Engineering \& Technology, A. B. Road, Guna, India \\ ${ }^{2}$ Electronics and Communication Dept., Universitat Ramon Llull, Barcelona, Spain \\ sanjeevdu2010@rediffmail.com, \{rajesh.vishwakarma, ravi.kumar\}@juet.ac.in, \\ \{jaume.anguera, aurora.andujar\}@fractus.com \\ Submitted July 30, 2016 / Accepted June 9, 2017
}

\begin{abstract}
A single layer coaxial fed rectangular microstrip slotted antenna for circular polarization (CP) is proposed for radio frequency identification (RFID) application. Two triangular shaped slots and one rectangular slot along the diagonal axis of a square patch have been embedded. Due to slotted structure along the diagonal axis and less surface area, good quality of circular polarization has been obtained with the reduction in the size of microstrip antenna by $4.04 \%$. Circular polarization radiation performance has been studied by size and angle variation of diagonally slotted structures. The experimental result found for $10 \mathrm{~dB}$ return loss is $44 \mathrm{MHz}$ with $10 \mathrm{MHz}$ of $3 \mathrm{~dB}$ Axial Ratio (AR) bandwidth respectively at the resonant frequency $910 \mathrm{MHz}$. The overall proposed antenna size including the ground plane is $80 \times 80 \times 4.572 \mathrm{~mm}^{3}$.
\end{abstract}

\section{Keywords}

Circularly polarized, microstrip antenna, radio frequency identification

\section{Introduction}

Recently, the RFID (radio frequency identification) has become very popular which is an electronic identification technology that uses radio EM waves to exchange data between reader and tag antennas i.e. an object basically used in commercial applications. The common examples are UHF band (840-960 MHz) RFID systems becoming more attractive for many applications such as supply chain, tracking, bioengineering, inventory management, large information storage capacity, logistics etc. [1-3]. Generally, the UHF tag antennas are linearly polarized but the orientations of the tag antennas are random, so actual application and requirement of RFID tag antennas are circularly polarized systems [4]. Circularly polarized microstrip antenna reduces the multipath effect generated by misalignment of reader and tag antennas and becomes most effective and efficient RFID system. Therefore recently, RFID antennas are usually circularly polarized [5], [6]. The total frequency range of the UHF band used for RFID system is $840-960 \mathrm{MHz}$. However, the frequency band for RFID application is different for different countries. In America, operating band is $902-928 \mathrm{MHz}$, in Europe $865-867 \mathrm{MHz}$, in India $865-867 \mathrm{MHz}$, in China 840.5-844.5 MHz and $920.5-924.5 \mathrm{MHz}$, in Japan 952-955 MHz etc. [7], [8]. In general, circular polarization commonly needs two orthogonal linear polarizations with 90 degree phase shift difference [9]. Generally, circular polarization antenna is divided into two types: single feed and multi feed technique types. A single feed CP antenna is simple and compact with respect to dual or multi-feed $\mathrm{CP}$ antenna but these antennas have a disadvantage of narrow bandwidth and AR 1-4\% [10],[11]. The major consideration for the CP microstrip antenna design of handheld/ portable RFID reader applications is that it must cover at least one UHF RFID band with a bandwidth of few $\mathrm{MHz}$ [12], [13]. A compact, circularly polarized, slotted-slit loaded square patch is used to generate circular polarization by using two unequal sizes of circular slots along the diagonal axis of the patch with slits to reduce the size [14].

Recently, a reduced size CP arrowhead shaped slot is embedded in the first quadrant center of the radiator square patch to achieve 10-dB return loss bandwidth of $35.0 \mathrm{MHz}$ (888.0-923.0 MHz) and 3-dB AR bandwidth (ARBW) of $8 \mathrm{MHz} \quad(908.0-916.0 \mathrm{MHz})$ with overall size $87 \times 87 \times 4.572 \mathrm{~mm}^{3}[15]$.

In this paper, a single layer coaxial fed circularly polarized microstrip antenna with two asymmetrical triangular slots embedded in it has been proposed. Due to these two asymmetrical slots entrenched diagonally into the square patch, the circular polarization is being generated. A rectangular slot is cut along the diagonal axis in order to improve the impedance matching. A good quality $\mathrm{CP}$ has been achieved by adjusting the size of the slots. The proposed structure gives large bandwidth and large AR bandwidth. 


\section{Antenna Geometry Design}

The theoretical results considered here are based with the assumption that a sinusoidal basis function on patch antenna in a direction of resonance is sufficient to approximate the current distribution. Multi-frequency behavior of patch antenna can be obtained by means of multiple radiating elements, which supports strong currents and radiation at resonance. These types of configurations include multi slot patch antennas fabricated by using circular, annular, rectangular and triangular slots in it. The physics behind the design is to create an asymmetric slot object so as to create two degenerate modes, one in $\mathrm{X}$ and the other in Y direction. Since we want to have two orthogonal modes $90^{\circ}$ out of phase, the slot/slots in the patch should be not symmetric. In this manner, the length of the currents in the $\mathrm{X}$ direction travels a slightly different path than the currents in $\mathrm{Y}$ direction. This different length is optimized so as to create the needed $90^{\circ}$ out of phase to create the circular polarization. The triangular slot as well as rectangular slot has four components of the current distribution for all the quadrants with $0^{\circ}, 90^{\circ}, 180^{\circ}$ and $270^{\circ}$. It is clearly visible that the current distribution for all the slots is being polarized towards left hand side from the antenna face. The current distribution for the triangular slot patch reveals that they are approximately similar to those of the rectangular slot patch with the exception that the antenna exhibits a cross polarized component in the $\mathrm{E} \& \mathrm{H}$ plane. However since for the same resonant frequencies, the triangular slot antenna requires less patch area, this property has been exploited to get the application advantage for RFID in this paper.

The double asymmetrical triangular with rectangular shaped slotted microstrip antenna is proposed with a reduction in antenna size (Fig. 1). The radiating square patch has length and width $L_{\mathrm{p}}$ and $W_{\mathrm{p}}$, respectively. The single layer antenna designed on the FR4 substrate with dielectric

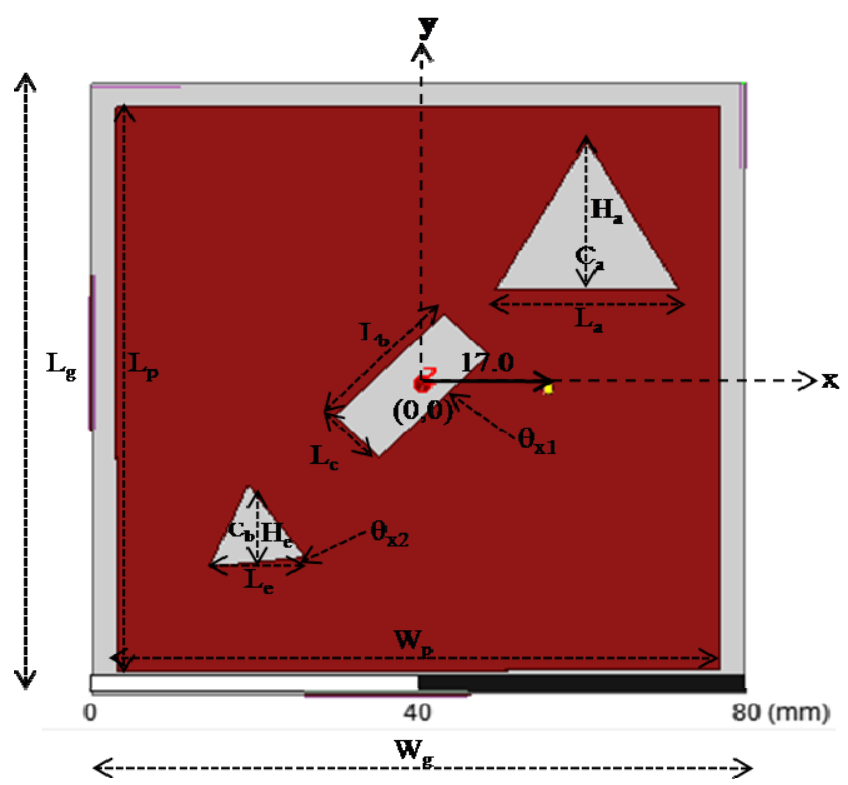

Fig. 1. The proposed antenna geometry.

\begin{tabular}{|c|c|c|c|c|}
\hline$L_{\mathrm{g}}$ & $W_{\mathrm{g}}$ & $L_{\mathrm{p}}$ & $W_{\mathrm{p}}$ & $L_{\mathrm{a}}$ \\
\hline 80 & 80 & 74 & 74 & 22 \\
\hline$H_{\mathrm{a}}$ & $L_{\mathrm{b}}$ & $L_{\mathrm{c}}$ & $L_{\mathrm{e}}$ & $H_{\mathrm{e}}$ \\
\hline 19 & 19 & 7.6 & 11 & 9 \\
\hline
\end{tabular}

Tab. 1. Dimensions of antenna in millimeter.

constant 4.4 and thickness $h 4.572 \mathrm{~mm}$ and loss tangent 0.02 . Size of the substrate is $80 \mathrm{~mm} \times 80 \mathrm{~mm}$ and the overall size is $80 \times 80 \times 4.572 \mathrm{~mm}^{3}$. Length and width of the rectangular slot are $L_{\mathrm{b}}$ and $L_{\mathrm{c}}$. By adjusting the length of the triangle to optimize in $x$ and $y$ direction, $L_{\mathrm{a}}>L_{\mathrm{e}}$ and $H_{\mathrm{a}}>H_{\mathrm{e}}$ where $L_{\mathrm{a},} L_{\mathrm{e}}, H_{\mathrm{a}}$ and $H_{\mathrm{e}}$ are the base length and height of triangular slots respectively. The location of the two triangular slots is at the first and the third quadrant along the diagonal axes. To achieve CP operation of the antenna the area of triangles should be unequal. All the dimensional parameters of the antenna are shown in Table 1.

\section{Parametric Analysis}

The proposed antenna has dimensions $74 \mathrm{~mm}\left(L_{\mathrm{p}}\right) \times$ $74 \mathrm{~mm}\left(W_{\mathrm{p}}\right)$ and substrate size of $80 \mathrm{~mm}\left(L_{\mathrm{g}}\right) \times 80 \mathrm{~mm}$ $\left(W_{\mathrm{g}}\right)$ (Fig. 1). This antenna has been simulated using 3DElectromagnetic software i.e. Ansoft HFSS, based on finite element method. The critical design parameters are based on length and height of the triangle and the length and width of rectangular slots having a strong influence on characteristics of the antenna. Two unequal triangle slots are located in the first and the third quadrant diagonally on the radiator patch antenna. The coordinate of the first triangle is $C_{\mathrm{a}}(20.8,20.8)$ and the coordinate of the second triangular is $C_{\mathrm{b}}(-19.3,-20.3)$ with respect to the center of the patch. The probe feed location is on the positive $x$-axis direction at $17 \mathrm{~mm}$ from the center of the ground plane. Slight variations in the dimensions of the triangular slots excited the CP. For the realization of circular polarization radiation, asymmetrical triangular slotted patch antenna must have a 90 degree phase shift between two orthogonal modes of the electric field. These two orthogonal modes are produced by asymmetries along the diagonal axis of the radiator patch using triangular slots and the impedance matching conditions can be obtained by entrenching rectangular slot along the diagonal axis of the radiating patch which has been shown in Fig. 2(a),(b). The proposed antenna has good circular polarization radiation with a reduction in antenna patch size. A slot perturbing the modes is what matters to generate the circular polarization. A triangular slot has been proposed in order to show that an arbitrary shape can be useful to obtain circular polarization: position and size are the important parameters for the design rather than slot shape.

In Fig. 2(a), the simulated result of the basic patch antenna without any slot has been shown and Fig. 2(b) represents the simulated result of the proposed antenna. It is observed that without any slot, the resonance frequency 
is obtained at $930 \mathrm{MHz}$ with a very low impedance bandwidth. Embedding the two asymmetrical triangular slots with a rectangular slot, resonance frequency shifts towards the lower frequency range with better impedance bandwidth as well as AR bandwidth. It significantly increased in impedance bandwidth shown in Fig. 2(b) at $910 \mathrm{MHz}$ resonance frequency. In this condition, all other parameters are kept with the same values as listed in Tab. 1.

The proposed geometry (area $80 \times 80 \times 4.572 \mathrm{~mm}^{3}$ including the ground plane) shown in Fig. 2(b), gives better impedance bandwidth as compared to a simple square patch antenna in shown in Fig. 2(a). To determine the circularly polarized waves of the proposed microstrip antenna, the simulated surface current distributions at $910 \mathrm{MHz}$ are shown in Fig. 3. Figure 3(c)-(f) shows the direction of the distributed current at different time phase from 0 degree to 270 degree with a 90 degree interval. It shows that the surface current of the patch radiator is in the clockwise direction which results in exciting a left handed circular polarization (LHCP) radiation.

The length of the ground plane has been optimized from $76 \mathrm{~mm}$ to $84 \mathrm{~mm}$ to obtain the best result at $80 \mathrm{~mm}$. Therefore, the ground plane size of $80 \mathrm{~mm}$ is selected as the optimum size for a better result at $910 \mathrm{MHz}$ resonance frequency. It is known that the resonance frequency shifts towards the lower size band, with an increase in patch size. The reason for this shifting is that the resonance frequency is inversely proportional to the patch size but an improved impedance bandwidth of the radiating patch is obtained at patch size of $74 \mathrm{~mm}$ for a resonance frequency around $910 \mathrm{MHz}$. Figure 4 shows the simulation results of reflection coefficient against the frequency for the single triangular slot, double triangular slot and the proposed asymmetrical triangular slotted antenna geometry. It is found that when the number of the slotted area on the radiating patch increases, the resonance frequency of the antenna is reaching towards the desired frequency, which leads to a reduction in the antenna size. This is due to a longer current path [16]. Figure 5 shows the simulated results of AR against the frequency for a single triangular slot, double triangular slot and the proposed asymmetrical triangular slotted antenna. It is also found that AR frequency decreases with increase in slotted area on the patch radiator. This is due to increases in the electrical size of the antenna with the increased slotted area size on the patch radiator. Other important parameters are width and length of the rectangular slot which gives the impedance matching. Increasing or decreasing the width enhances or weakens the electromagnetic coupling between the feed line and the patch, which affects the impedance bandwidth.

The effect on the reflection coefficient bandwidth with respect to the variation of widths of rectangular slot $\left(L_{\mathrm{c}}\right)$ is as shown in Fig. 6. The width and length of rectangle optimizes to $7.6 \mathrm{~mm}$ and $19 \mathrm{~mm}$ respectively.

The width of the rectangle is varied from $6.8 \mathrm{~mm}$ to $8.0 \mathrm{~mm}$ with a step size of $0.4 \mathrm{~mm}$ while keeping the length $19 \mathrm{~mm}$, patch length $74 \mathrm{~mm}$ and the feed location
$17 \mathrm{~mm}$. As the width increases, the impedance matching improves and AR frequency decreases at lower frequency side approaching near $50 \Omega$ input impedance with the im-

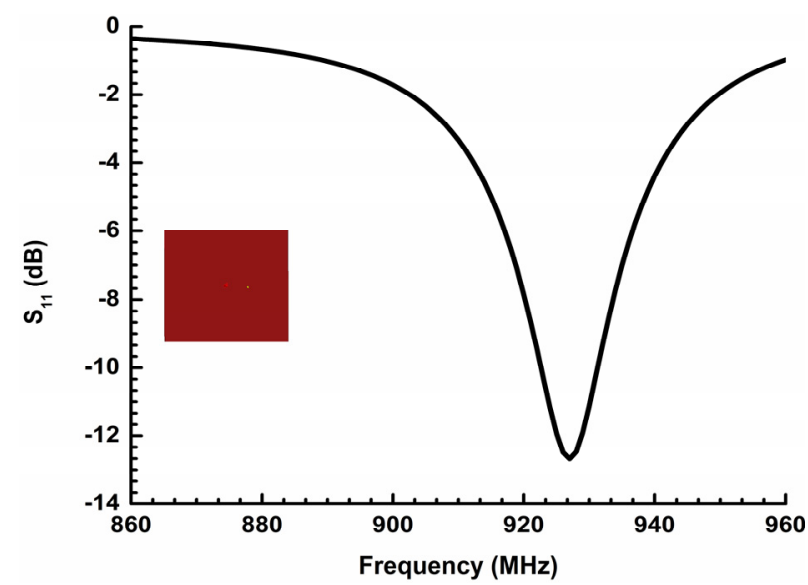

(a)

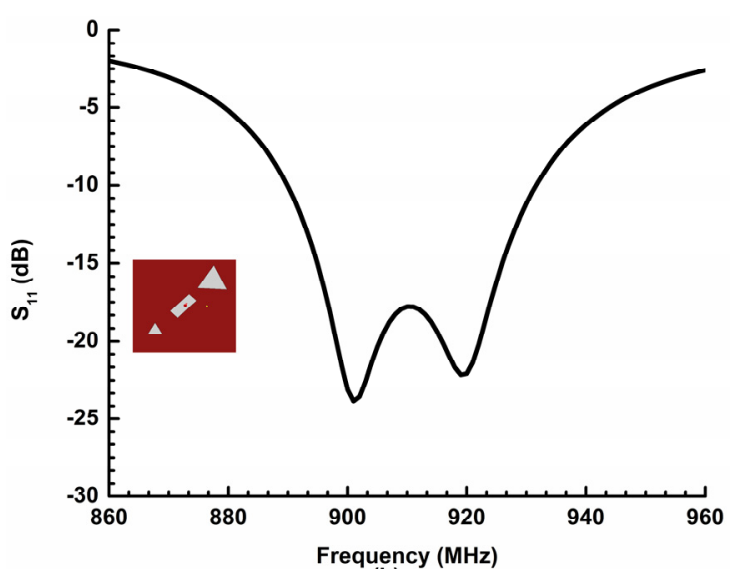

(b)

Fig. 2. (a) Simulated reflection coefficient of the patch antenna without any slot and (b) Simulated reflection coefficient of the proposed double asymmetrical triangular slotted antenna.

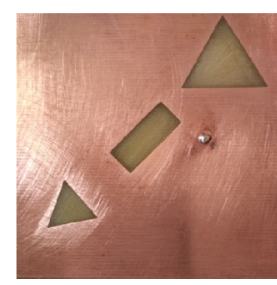

(a)

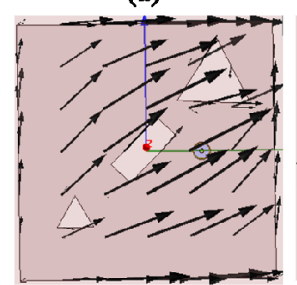

(d)

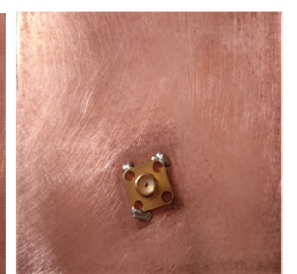

(b)

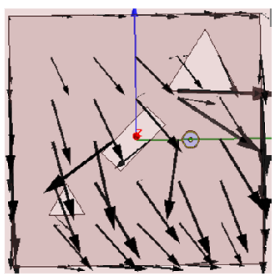

(c)

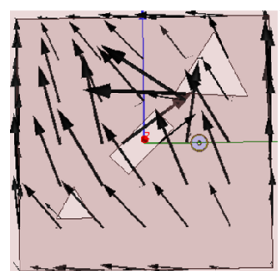

(c)

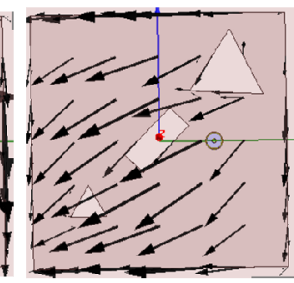

(f)
Fig. 3. (a)-(b) Fabricated prototype proposed antenna front view and back view and simulated surface current distribution at $910 \mathrm{MHz}$ : (c) $0^{\circ}$, (d) $90^{\circ}$, (e) $180^{\circ}$, (f) $270^{\circ}$ 


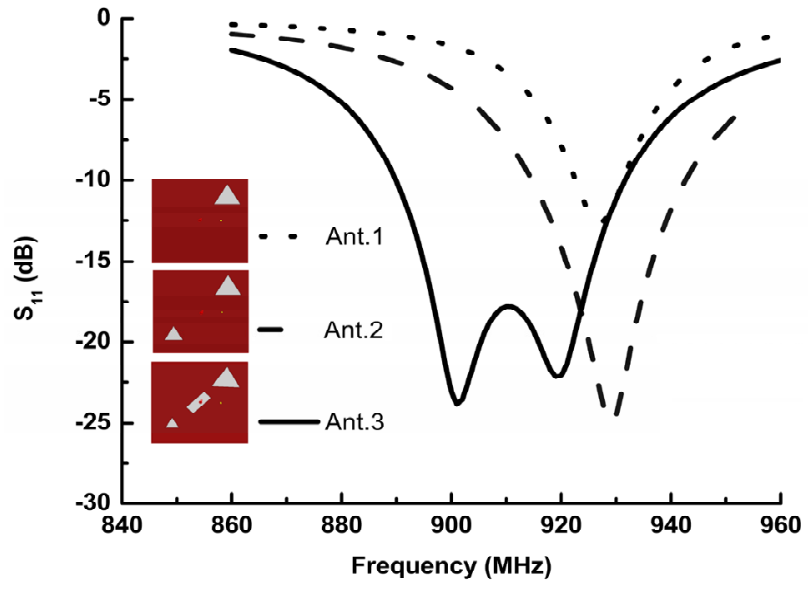

Fig. 4. Simulated reflection coefficient vs. frequency for the single triangular slot (Ant.1), double triangular slot (Ant.2) and the proposed asymmetrical triangular slot (the proposed antenna (Ant.3)).

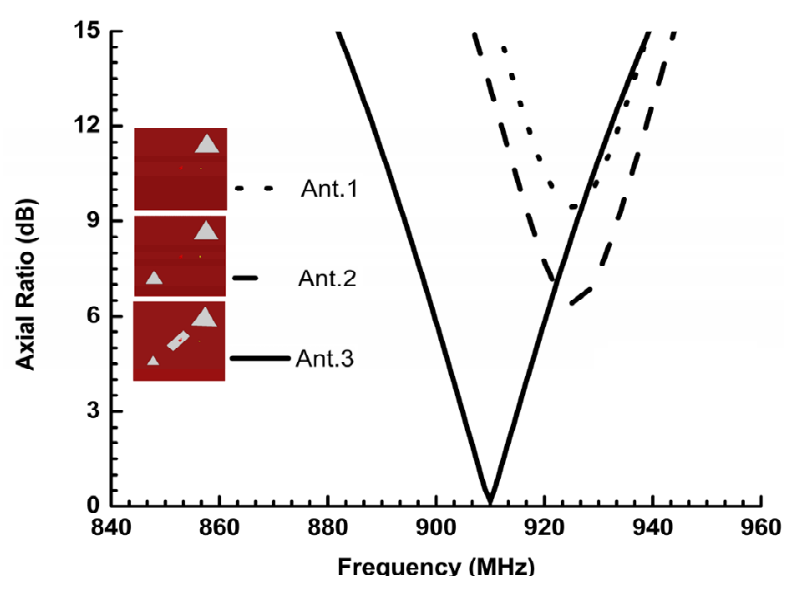

Fig. 5. Simulated AR vs. frequency for the single triangular slot (Ant.1), double triangular slot (Ant.2) and the proposed asymmetrical triangular slot (the proposed antenna (Ant.3))

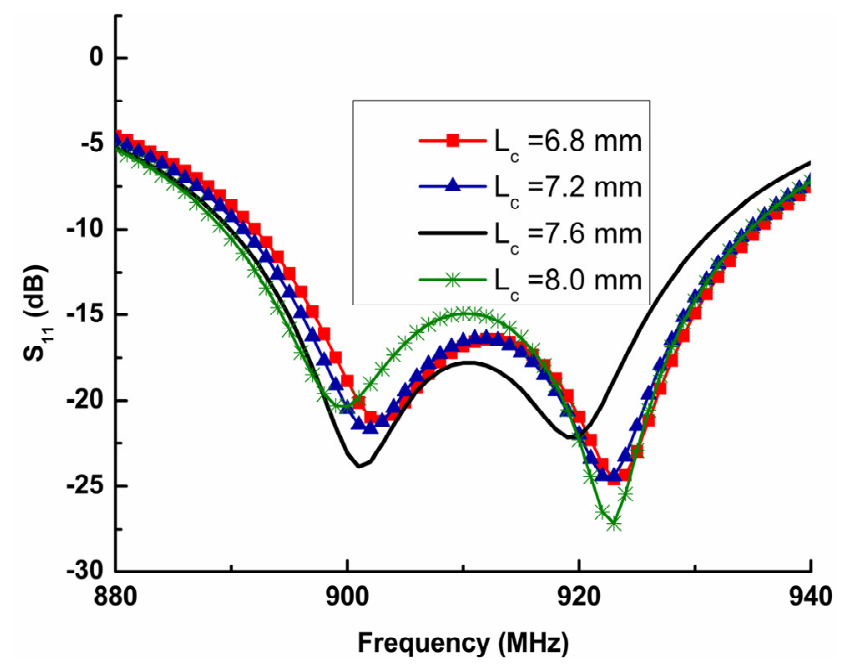

Fig. 6. Simulated reflection coefficient against frequency with various width size of rectangular slot $\left(L_{\mathrm{c}}\right)$.

provement found in $10 \mathrm{~dB}$ return loss bandwidth. The best minimum AR result obtained at $7.6 \mathrm{~mm}$ in the proposed antenna structure. Figure 7 shows the variation of rectan-

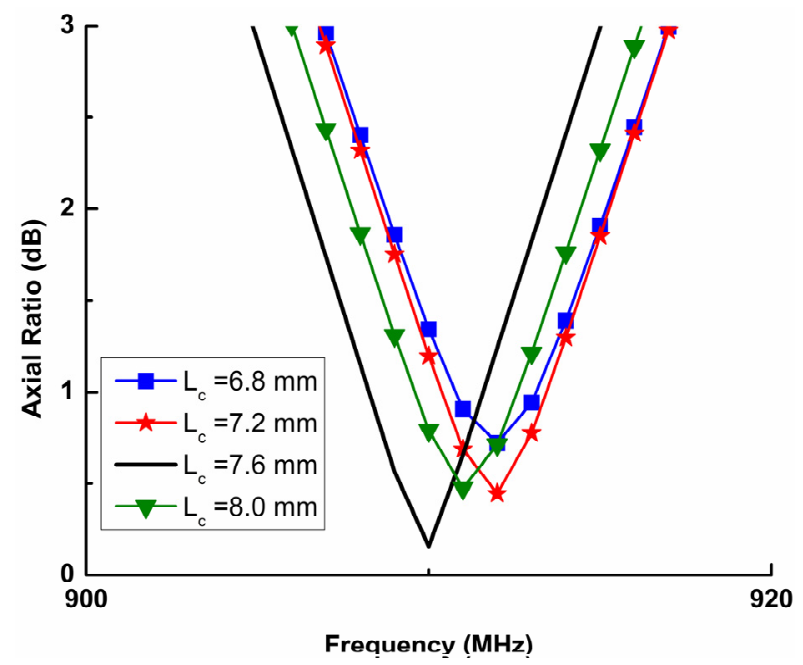

Fig. 7. Simulated AR against frequency with various width size of rectangular slot $\left(L_{\mathrm{c}}\right)$.

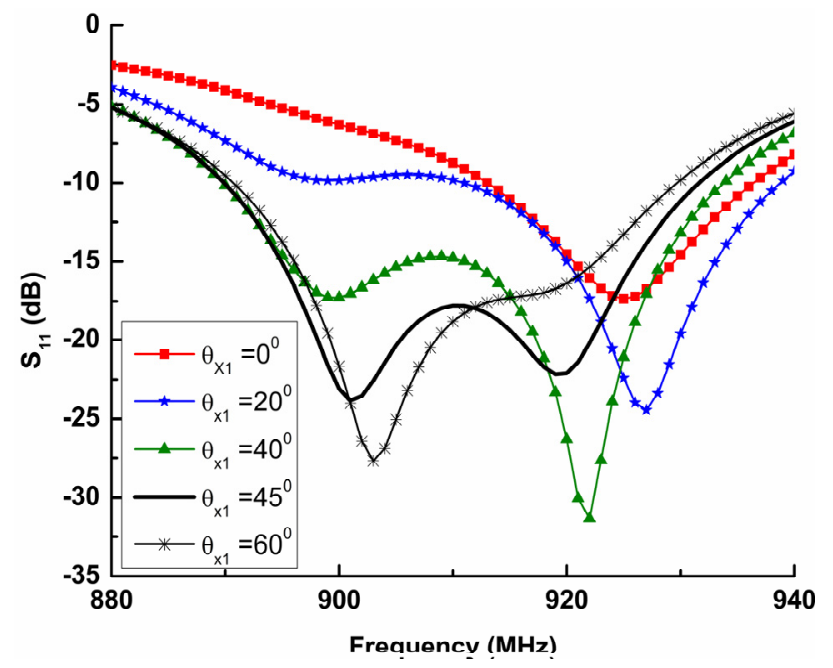

Fig. 8. Simulated reflection coefficient with various inclined angle of $\theta_{\mathrm{x} 1}$.

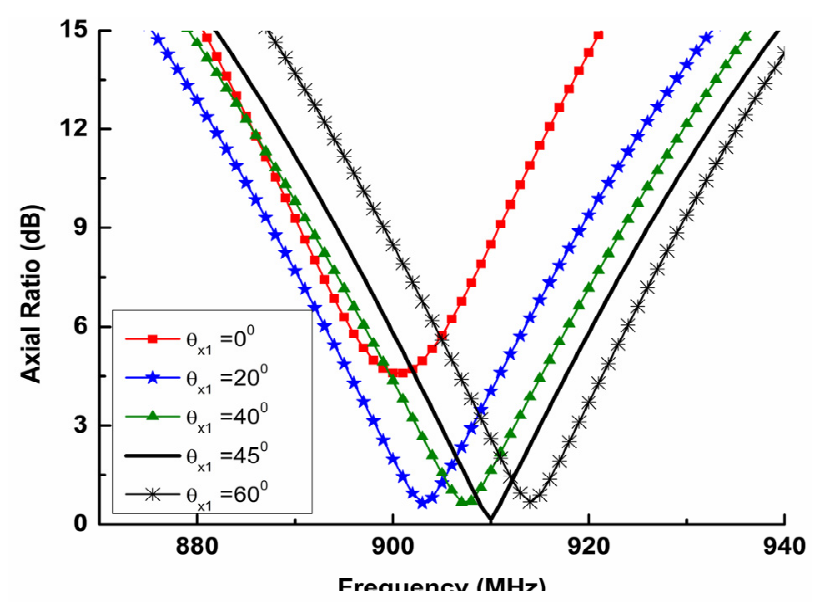

Fig. 9. Simulated axial ratio with various inclined angle of $\theta_{\mathrm{x} 1}$

gular slot width from $6.8 \mathrm{~mm}$ to $8.0 \mathrm{~mm}$ with a step size of $0.4 \mathrm{~mm}$ and keeping other parameters constant. The first larger triangular slot (Ant.1) gave only the return loss near about the value $13.5 \mathrm{~dB}$ at $929 \mathrm{MHz}$ with axial ratio of $9.2 \mathrm{~dB}$ around $925 \mathrm{MHz}$ which are not desired and as per 
the design requirements as shown in Fig. 4 and Fig. 5. To improve this, the second smaller triangular slot (Ant.2) was entrenched diagonally in the patch which makes the current distribution around $45^{\circ}$ similar to as shown in Fig. 3(c-f) with respect to the existing distribution of the larger triangular slot patch. This slot makes the result more improved in terms of return loss around $26 \mathrm{~dB}$ but at $928 \mathrm{MHz}$ which is again off the required frequency range. Moreover the axial ratio also improved to $5.8 \mathrm{~dB}$ with this second triangular slot which is found at $924 \mathrm{~dB}$ but again off the required frequency. Hence the third slot i.e. rectangular slot (Ant.3) was entrenched in the patch by angle $\theta_{\mathrm{x} 1}$ with respect to $\mathrm{X}$-axis so as to get the desired return loss and axial ratio at $910 \mathrm{MHz}$ including the circularly polarization with increase in electrical length and reduced patch area i.e. antenna size. This rotation of $\theta_{\mathrm{x} 1}$ has been experimented for different values i.e. $0^{\circ}, 20^{\circ}, 40^{\circ}, 45^{\circ}$ and $60^{\circ}$ to further improve the return loss and axial ratio as shown in Fig. 8 and Fig. 9 which concludes that the best possible result for $\theta_{\mathrm{x} 1}$ was found at an angle of $45^{\circ}$. Though all the slots are showing the behavior of circular polarization for them but the impact of rectangular slot current distribution is the most contributing part in the circular polarization of this antenna design. At this stage, there is a loss of coupling between the resonances developed by the triangular slots due a dimension difference. Such a decoupling is reduced by the small rotation of the axis of smaller triangular slot. This is clearly seen, where experimenting with and increasing the inclination angle $\theta_{\mathrm{x} 2}$ to $3.28^{\circ}$ has only resulted in some shifts in the desired resonant frequencies with the best possible improvement in return loss. Now the improved result with the total bandwidth of $44 \mathrm{MHz}$ at the $10 \mathrm{~dB}$ return loss is found on the desired frequency range for the RFID applications.

\section{Result and Discussion}

The proposed slotted circularly polarized microstrip antenna for RFID application has been optimized at around $910 \mathrm{MHz}$ UHF band using a rectangular slot length $L_{\mathrm{b}}$ of $19 \mathrm{~mm}$ and width $L_{\mathrm{c}}$ of $7.6 \mathrm{~mm}$. The antenna of parameters listed in Tab. 1 has been fabricated and measured to compare the simulated results. The return loss for manufactured antenna was found as $17.9 \mathrm{~dB}$ as shown in Fig. 10 which was measured with a vector network analyzer at an operating frequency of $910 \mathrm{MHz}$. The measured result is quite comparable with the simulated results and concluded that the bandwidth of $44 \mathrm{MHz}$ has been found with $10 \mathrm{~dB}$ return loss.

The measured $3 \mathrm{~dB}$ axial plot points out that minimum AR value of $0.19 \mathrm{~dB}$ is achieved at the center frequency as shown in Fig. 11. To measure the AR first the co- and cross- radiation patterns for the $\mathrm{XZ}$ have been measured, then the ratio of co- and cross- is taken to calculate the AR taking the consideration the phase. The $3 \mathrm{~dB}$ AR bandwidth has been found as $10 \mathrm{MHz}$. To measure the gain of a $\mathrm{CP}$ antenna the co- and cross- radiation patterns in both the planes ( $\mathrm{XZ}$ and $\mathrm{YZ}$ ) are measured and then combined to get the $\mathrm{CP}$ gain. Figure 12 shows the maximum gain of $3.12 \mathrm{dBic}$ for the proposed antenna structure. Reasonably good agreement between the simulated and measured results is being observed as shown in the respective figures. The small difference between the simulated and measured results may be due the effect of SMA connector soldering and tolerance levels during the fabrication process of the antenna. Overall the proposed result is found better than the results shown for the structures proposed in [7], [11], [13] and [15].

Table 2 shows the comparison of the proposed antenna results with the related published compact CP microstrip antenna structures. The proposed asymmetrical double triangular slotted circularly polarized microstrip antenna is compact in size and gives better results as compared to others listed in Tab. 2. The presented antenna generates wide $3 \mathrm{~dB}$ bandwidth and provides minimum $\mathrm{AR}$ value at the center frequency. Figure 13 shows the measured and simulated radiation pattern of the proposed MSA. It is observed that the maximum gain (simulated) is $3.12 \mathrm{dBic}$ at $910 \mathrm{MHz}$ and measured gain is $3.07 \mathrm{dBic}$ covering the entire operating band.

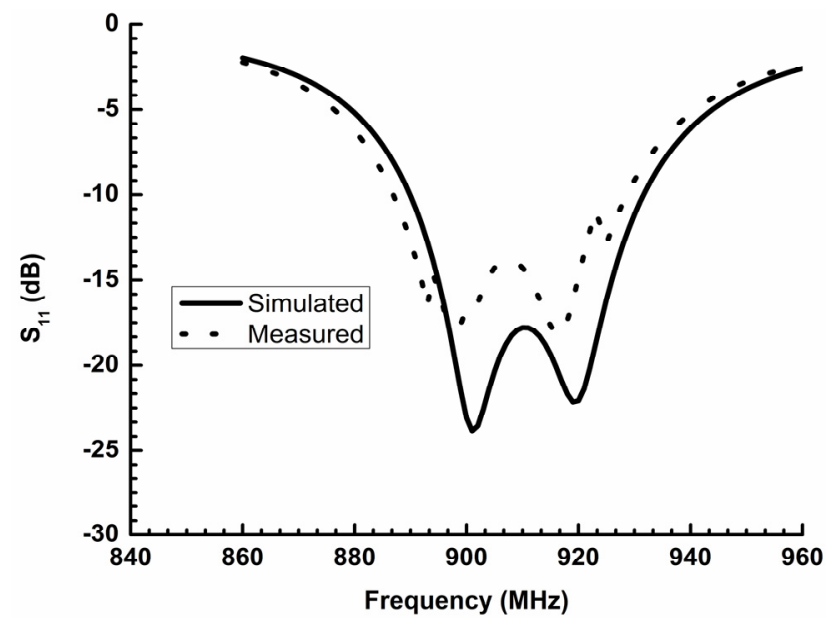

Fig. 10. Impedance bandwidth of antenna.

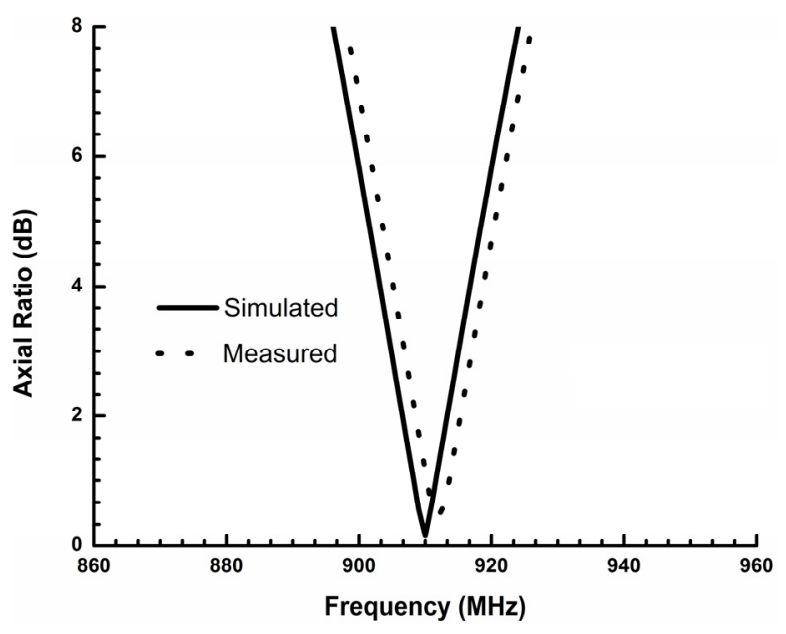

Fig. 11. Axial ratio for the proposed antenna. 


\begin{tabular}{|c|c|c|c|c|c|c|}
\hline Antenna & Description & $\begin{array}{c}\text { 10-dB return loss } \\
\text { bandwidth (MHz) }\end{array}$ & $\begin{array}{c}\text { 3-dB axial ratio } \\
\text { bandwidth (MHz) }\end{array}$ & $\begin{array}{c}\text { Overall antenna size } \\
\left(\mathbf{m m}^{\mathbf{3}}\right)\end{array}$ & $\begin{array}{c}\text { Operating frequency } \\
\text { of CP (MHz) }\end{array}$ & $\begin{array}{c}\text { Gain } \\
(\mathbf{d B i c})\end{array}$ \\
\hline Ref.[7] & $\begin{array}{c}\text { Asymmetrical } \\
\text { circular slotted }\end{array}$ & 17 & 6 & $90 \times 90 \times 4.566$ & 900 & 3.70 \\
\hline Ref.[11] & $\begin{array}{c}\text { CP cross shaped } \\
\text { slotted }\end{array}$ & 18 & 6 & $90 \times 90 \times 4.286$ & 910 & 3.80 \\
\hline Ref.[13] & $\begin{array}{c}\text { Compact CPMA for } \\
\text { RFID }\end{array}$ & 19 & 4 & $90 \times 90 \times 4.572$ & 920 & 3.40 \\
\hline Ref.[15] & $\begin{array}{c}\text { Arrowhead shaped } \\
\text { slotted }\end{array}$ & 35 & 8 & $87 \times 87 \times 4.572$ & 911 & 4.50 \\
\hline Proposed & $\begin{array}{c}\text { Slotted CPMA for } \\
\text { RFID }\end{array}$ & $\mathbf{4 4}$ & $\mathbf{1 0}$ & $\mathbf{8 0} \times \mathbf{8 0} \times \mathbf{4 . 5 7 2}$ & $\mathbf{9 1 0}$ & $\mathbf{3 . 0 7}$ \\
\hline
\end{tabular}

Tab. 2. Comparison of compact CP microstrip antenna.

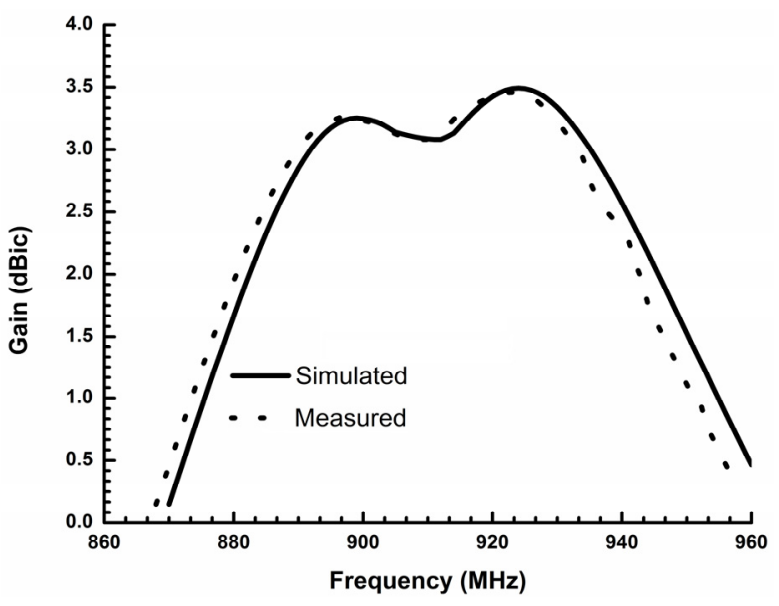

Fig. 12. Gain of antenna measure in the normal direction to the patch.
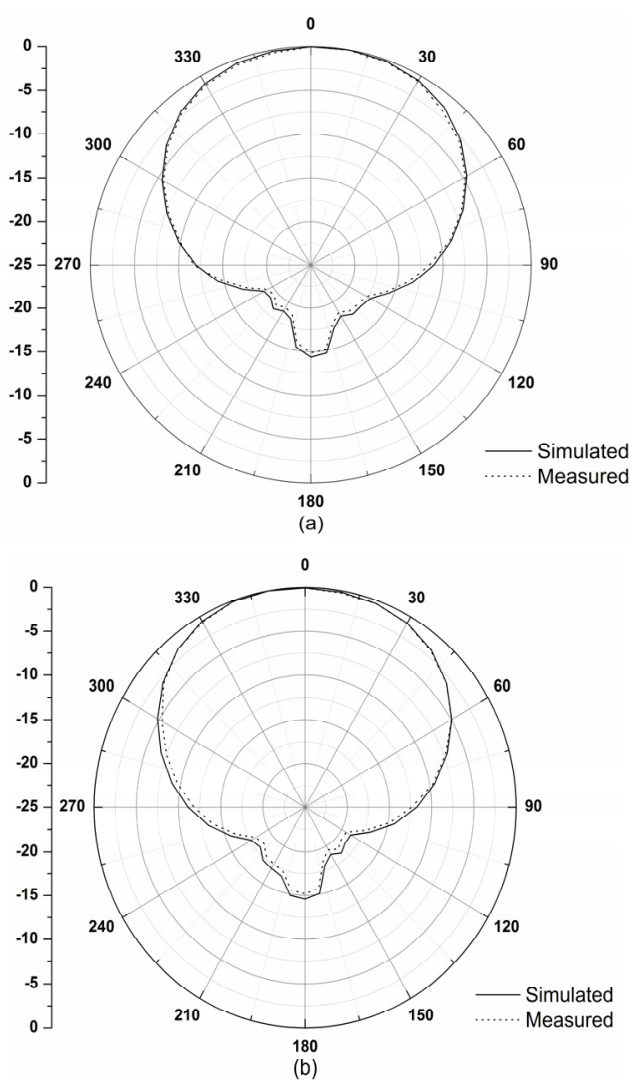

Fig. 13. Radiation pattern of proposed antenna at $910 \mathrm{MHz}$ : (a) $\varphi=0^{\circ}$, (b) $\varphi=90^{\circ}$.

\section{Conclusion}

A circular polarized slotted microstrip patch antenna has been successfully simulated and manufactured. The prototype with an overall size of $80 \times 80 \times 4.57 \mathrm{~mm}^{3}$ achieved a $10 \mathrm{~dB}$ return loss bandwidth of $44.0 \mathrm{MHz}$ (889.0-933.0 MHz) and $3 \mathrm{~dB}$ AR band width of $10.0 \mathrm{MHz}$ (904.0-914.0 MHz). The smaller sized proposed antenna design can be easily manufactured for portable UHF RFID reader applications. The antenna has been compared with other schemes showing a better bandwidth both in terms of return loss and AR.

\section{Acknowledgment}

The authors would like to thank Dr. B. K. Kanaujia, ECE department, AIACTR, Delhi for proving fabrication, measurement and valuable guidance.

\section{References}

[1] WANT, R. An introduction to RFID technology. IEEE Pervasive Computing, 2006, vol. 5, no. 1, p. 25-33. DOI: 10.1109/MPRV.2006.2

[2] CHUNG, H. L., QING, X., CHEN, Z. N. A broadband circularly polarized stacked probe fed patch antenna for UHF RFID application. International Journal of Antenna and Propagation, 2007, p. 1-9. DOI: $10.1155 / 2007 / 76793$

[3] KWA, H. W., QING, X., CHEN, Z. N. Broadband single fed single patch polarized antenna for UHF RFID applications. In IEEE Antenna and Propagation Society International Symposium. San Diego (CA, USA), 2008, p. 1-4. DOI: 10.1109/APS.2008.4619871

[4] XIAO, Y., YU, S., WU, K., et al. Radio frequency identification technologies, applications and research issues. Wireless Communication and Mobile Computing, 2007, vol. 7, no. 4, p. $457-472$. DOI: $10.1002 / \mathrm{wcm} .365$

[5] JUNG, Y. K., LEE, B. Dual band circularly polarized microstrip RFID reader antenna using metamaterial branch line coupler. IEEE Transactions on Antennas and Propagation, 2012, vol. 60, no. 2, p. 786-791. DOI: 10.1109/TAP.2011.2167943

[6] CHEN, Z. N., QING, X., CHUNG, H. L. A universal UHF RFID reader antenna. IEEE Transactions on Microwave Theory and 
Techniques, 2009, vol. 57, no. 5, p. 1275-1282. DOI: 10.1109/TMTT.2009.2017290

[7] NASIMUDDIN, CHEN, Z. N., QING, X. Asymmetrical circular shaped slotted microstrip antenna for circular polarization and RFID applications. IEEE Transactions on Antennas and Propagation, 2010, vol. 58, no. 12, p. 3821-3828. DOI: 10.1109/TAP.2010.2078476

[8] TONG, K. F., WONG, T. P. Circularly polarized U slot antenna. IEEE Transactions on Antennas and Propagation, 2007, vol. 55, no. 8, p. 2382-2385. DOI: 10.1109/TAP.2007.901930

[9] BALANIS, C. A. Antenna Theory: Analysis and Design. $3^{\text {rd }}$ ed. New Delhi (India): Wiley India Pvt. Ltd., 2011. ISBN: 978-81265-2422-8

[10] TSAI, C. L. A coplanar strip dipole antenna for broadband circular polarization operation. Progress in Electromagnetic Research, 2011, vol. 121, p. 141-157. DOI: 10.2528/PIER11082407

[11] NASIMUDDIN, CHEN, Z. N., QING, X. A compact circularly polarized cross shaped slotted microstrip antenna. IEEE Transactions on Antennas and Propagation, 2012, vol. 60, no. 3 , p. 1584-1588. DOI: 10.1109/TAP.2011.2180334

[12] POZAR, D. M., DUFFY, S. M. A dual band circularly polarized aperture coupled stacked microstrip antenna for global positioning satellite. IEEE Transactions on Antennas and Propagation, 1997, vol. 45, no. 11, p. 1618-1625. DOI: 10.1109/8.650073

[13] NASIMUDDIN, QING, X., CHEN, Z. N. Compact circularly polarized microstrip antenna for RFID handheld reader applications. In Asia Pacific Microwave Conference. Singapore, Dec. 2009, p. 1950-1953. DOI: 10.1109/APMC.2009.5385294

[14] NASIMUDDIN, CHEN, Z. N., QING, X. A compact circularly polarized slotted slit microstrip patch antenna. In Proceeding of the Asia-Pacific Microwave Conference. Dec. 2011, p. 582-585. INSPEC Accession number: 15655685

[15] GAUTAM, A. K., KUNWAR, A., KANAUJIA, B. K. Circularly polarized arrowhead shape slotted microstrip antenna. IEEE Antennas and Wireless Ppropagation Letters, 2014, vol. 13, p. 471-474. DOI: 10.1109/LAWP.2014.2309719

[16] ANGUERA, J., BOADA, L., PUENTE, C., et al. Stacked Hshaped microstrip patch antenna. IEEE Transactions on Antennas and Propagation, 2004, vol. 52, no. 4, p. 983-993. DOI: 10.1109/TAP.2004.825812

\section{About the Authors...}

Sanjeev KUMAR was born in India. He received his Bachelor of Engineering degree in Electronics \& Communication Engineering from Sagar Institute of Research \& Technology, Bhopal, India in 2009. He received his M.Tech. Degree with specialization in Microwave \& Electronics from the University of Delhi, India in 2012. He is currently pursuing $\mathrm{Ph} . \mathrm{D}$. degree as a research scholar from the Dept. of Electronics \& Communication, Jaypee University of Engineering \& Technology, Guna, India. His research interest is circularly polarized microstrip antennas, UWB antennas and also includes the area RF circuit design.

Rajesh K. VISHWAKARMA was born in India. He received his B.Sc. and M.Sc. degree in Electronics from Dr. R. M. L. Avadh University, Faizabad, India in 1997 and 1999, respectively. He received his Ph.D. degree from the School of Studies in Electronics, Pandit Ravi Shankar
Shukla University, Raipur, India in 2013. He was also involved as a guest faculty at the Dept. of Computer Science, Banaras Hindu University, Varanasi. He is working as an Assistant Professor (Senior Grade) in the Dept. of Electronics and Communication Engineering, Jaypee University of Engineering \& Technology, Guna, M.P., India presently.

Ravi KUMAR was born in India. He received his Ph.D. from the Dept. of Electronics and Communication Engineering, Jaypee University of Engineering \& Technology, Guna in 2013 with the specialization in MIMO Communication Systems and Smart Antennas. He has eight months research experience as Project Associate in Radio and Science Division (RASD) department at National Physical Laboratory, New Delhi. He has served as a Centre Manager in Pentasoft Technologies Ltd., Bhopal. Currently he is working as an Assistant Professor (Senior Grade) in Jaypee University of Engineering and Technology, Guna, India. He has published several research papers in various journals of repute and also received one best paper award in IEEE Conference. He is senior member of IEEE and currently reviewer of IEEE Antenna and Wave Propagation Letters, IEEE Transactions on Vehicular Technology, International Journal of Microwave and Wireless Technologies published by Cambridge University press and Wireless Personal Communication published by Springer.

Jaume ANGUERA was born in Vinaròs, Spain, in 1972. He received the Technical Engineering degree in Electronic Systems and Engineering degree in Electronic Engineering, both from the Ramon Llull University (URL), Barcelona, Spain, in 1994 and 1998, respectively, and the Engineering and $\mathrm{Ph} . \mathrm{D}$ degrees in Telecommunication Engineering, both from the Polytechnic University of Catalonia (UPC), Barcelona, Spain, in 1998 and 2003, respectively. In 1997-1999 he joined the Electromagnetic and Photonic Engineering Group of the Signal Theory and Communications Department of the UPC as a researcher in microstrip fractal-shaped antennas. In 1999, he was a researcher at Sistemas Radiantes, Madrid, Spain, where he was involved in the design of a dual-frequency dual-polarized fractal-inspired microstrip patch array for mobile communications. In the same year, he is currently an Associate Professor at the Department of Electronics and Telecommunications, Universitat Ramon Llull-Barcelona, where he is currently teaching. He holds more than 100 granted invention patents and 30 more pending patents in the antenna field. He is author of more than 140 journals, international and national conference papers and he has directed more than 80 bachelor and master thesis. He is reviewer for the IEEE Transaction and Antennas and Propagation, IEEE Antennas and Wireless Propagation Letters, IEEE Antennas and Propagation Magazine, Progress in Electromagnetic Research (PIER), IEE Electronics Letters, and ETRI journal (Electronics and Telecommunications Research Institute, South Korea). He is editor of International Journal on Antennas and Propagation (IJAP). His biography is listed in Who's Who in the World, Who's Who in Science and Engineering, Who's Who in Emerging 
Leaders and in IBC (International Biographical Center, Cambridge-England).

Aurora ANDUJAR was born in Barcelona, Spain, 1984. She received the Bachelor's degree in Telecommunication Engineering specializing in Telecommunication Systems in 2005, the Master degree in Telecommunications Engineering in 2007, the Master of Science in Telecommunication Engineering and Management in 2007 from the Polytechnic University of Catalonia (UPC), and the Ph.D. from UPC in 2013, Barcelona, Spain. She has published more than 50 journals, international and national conference papers. She is also author of 15 invention patents in the antenna field. She has directed 20 bachelor and master thesis. In 2015 she received the best Doctoral Thesis (Ph.D.) in "Fundamentos y Tecnologías Básicas de la Información y las Comunicaciones y sus Aplicaciones" organized by Colegio Oficial de Ingenieros de Telecomunicación (COIT). Dr. Andujar is member of the COIT (Colegio Oficial de Ingenieros de Telecomunicación) and AEIT (Asociación Española de Ingenieros de Telecomunicación). She is editor of International Journal on Antennas and Propagation (IJAP). 